Article

\title{
Vegetation Dynamics and Associated Driving Forces in Eastern China during 1999-2008
}

\author{
Jian Peng ${ }^{1, *}$, You Li ${ }^{1}$, Lu Tian ${ }^{2}$, Yanxu Liu ${ }^{1}$ and Yanglin Wang ${ }^{1}$ \\ 1 Laboratory for Earth Surface Processes, Ministry of Education, College of Urban and \\ Environmental Sciences, Peking University, Beijing 100871, China; \\ E-Mails: sabonis_ren@163.com (Y.L.); liuyanxu@pku.edu.cn (Y.L.); \\ ylwang@urban.pku.edu.cn (Y.W.) \\ 2 Key Laboratory for Environmental and Urban Sciences, School of Urban Planning and Design, \\ Shenzhen Graduate School, Peking University, Shenzhen 518055, China; \\ E-Mail: 18604236913@163.com
}

* Author to whom correspondence should be addressed; E-Mail: jianpeng@ urban.pku.edu.cn.

Academic Editors: Yoshio Inoue and Prasad S. Thenkabail

Received: 1 June 2015 / Accepted: 10 October 2015 / Published: 20 October 2015

\begin{abstract}
Vegetation is one of the most important components of the terrestrial ecosystem and, thus, monitoring the spatial and temporal dynamics of vegetation has become the key to exploring the basic process of the terrestrial ecosystem. Vegetation change studies have focused on the relationship between climatic factors and vegetation dynamics. However, correlations among the climatic factors always disturb the results. In addition, the impact of anthropogenic activities on vegetation dynamics was indeterminate. Here, vegetation dynamics in 14 provinces in Eastern China over a 10-year period was quantified to determine the driving mechanisms relating to climate and anthropogenic factors using partial correlation analysis. The results showed that from 1999 to 2008, the vegetation density increased in the whole, with spatial variations. The vegetation improvement was concentrated in the Yangtze River Delta, with the vegetation degradation concentrated in the other developed areas, such as Beijing-Tianjin-Hebei Region and the Pearl River Delta. The annual NDVI changes were mainly driven by temperature in Northeast China and the Pearl River Delta, and by precipitation in the Bohai Rim; while in the Yangtze River Delta, the driving forces of temperature and precipitation almost equaled each other. Furthermore, the impact of anthropogenic activities on vegetation dynamics had accumulative effects in the time series, and had a phase effect on the vegetation change trend.
\end{abstract}


Keywords: vegetation dynamics; NDVI time series; climatic factor; anthropogenic activity; Eastern China

\section{Introduction}

Vegetation plays an important role in the mineral and energy cycle at a global level, adjusting the global carbon balance, decreasing the trend of rising greenhouse gas levels, such as carbon dioxide, as well as maintaining the global climate [1]. It is considered to be a sensitive index to environmental impact, as well as an indicator of global change. Therefore, monitoring vegetation dynamics effectively and accurately is the key to imitating the dynamics of the terrestrial ecosystem [2,3]. In other studies of global change, scientists have highlighted the close relationship among vegetation change, climate change, and anthropogenic activities [4]. In the long term, vegetation patterns and their changes are driven by natural and anthropogenic factors [5]. On the one hand, both natural and artificial vegetation grow under the influence of climatic factors, such as temperature and precipitation. On the other hand, vegetation change reflects climate change and anthropogenic interference. Thus, most studies focus on the relation between vegetation dynamics and climate, as well as the relation between vegetation dynamics and anthropogenic activities [6-10].

It was broadly confirmed that vegetation activities aggregate at mid to high latitudes in the Northern Hemisphere [11-14]. Many studies on vegetation dynamics monitoring have been carried out in $40^{\circ}-70^{\circ}$ northern latitude areas, most of whose results have shown the mean normalized difference vegetation index (NDVI) increased before 2000 [15-22]. However, because of the low spatial resolution of AVHRR, the study of vegetation dynamics using AVHRR GIMMS NDVI on regional scales has some uncertainties, which is especially unsuitable for urban studies [23-25]. Around 2000, the use of MODIS and SPOT-VGT products made it possible to increase the spatial resolution of NDVI, which reduced pixel size. Henceforth, year-by-year data from 2000 have become an effective choice of kilometer-scale vegetation dynamics studies.

As there are significant regional and local variations in vegetation dynamics, it is necessary to monitor the spatial patterns of vegetation dynamics, and to identify their driving forces. Warming climate reduced the range of snow cover and caused the vegetation turning green in advance in seasonal variations, and annual NDVI changes were also associated with temperature in spring and autumn in mid and high latitudes of the Northern Hemisphere [26-30]. In the northern and central plains of the USA, precipitation and potential evaporation were the most prevalent climate variables influencing vegetation dynamics [31-33]. In Amazon Basin, it was suggested net primary production (NPP) increased because of increasing solar radiation [14]. However, it is difficult to spatially quantify anthropogenic activities, because the statistical scale of anthropogenic activities such as economy and population is in mismatch with pixel resolution. Thus, how to quantify anthropogenic activities corresponding to the particular scale became one of the most important issues relating to the effects of such activities on vegetation [34]. In general, population density, urbanization, and economic level are usually used to quantify anthropogenic activities. For instance, Lu et al. concluded that NPP had a significant negative correlation with population density, gross domestic product (GDP) and residential location in Southeastern China [35]. 
$\mathrm{Xu}$ et al. analyzed the impact of urbanization on NPP in Jiangyin County, China, and the results showed that land cover changes triggered by urbanization reduced NPP directly [36]. Vegetation decrease triggered by land-cover changing to an impervious surface in urban areas can result in environmental threats with NPP reduction and surface temperature variation. Therefore, urbanization is one of the main anthropogenic activities affecting vegetation change.

Among the abundant studies on relations between vegetation dynamics and climate change, few look at temperature and precipitation separately. However, the shortcomings of neglecting the interaction between temperature and precipitation may bring uncertainties. In addition, the studies on the driving forces of anthropogenic activities on vegetation dynamics are still at an initial stage. Thus, relevant researches cannot comprehensively explain the driving mechanisms of vegetation dynamics [37,38]. In Eastern China there are three metropolitan areas forming the most developed region in China: Beijing-Tianjin-Hebei Region, Yangtze River Delta, and Pearl River Delta. Recently, the ecosystem of Eastern China changed significantly, influenced by both socioeconomic development and climate change. Therefore, this region deserves more attention when studying the effects of anthropogenic activities and climate change on vegetation dynamics. In this study, SPOT-VGT NDVI from 1999 to 2008 was used to monitor the vegetation dynamics and their driving forces in Eastern China. The objectives of this study were as follows: (i) to quantify temporal vegetation dynamics in Eastern China by trend analysis; and (ii) to analyze the correlation between vegetation dynamics, and climate, and anthropogenic activities using partial correlation analysis.

\section{Methodology}

\subsection{Study Area}

This study was carried out in Eastern China $\left(20^{\circ} 12^{\prime}-53^{\circ} 33^{\prime} \mathrm{N}, 109^{\circ} 45^{\prime}-135^{\circ} 05^{\prime} \mathrm{E}\right)$, including the following regions: Northeast China (including Heilongjiang, Jilin and Liaoning), Bohai Rim (including Beijing, Tianjin, Hebei and Shandong), Yangtze River Delta (including Jiangsu, Shanghai, Zhejiang, and Anhui), and Pearl River Delta (including Fujian, Jiangxi, and Guangdong) (Figure 1).
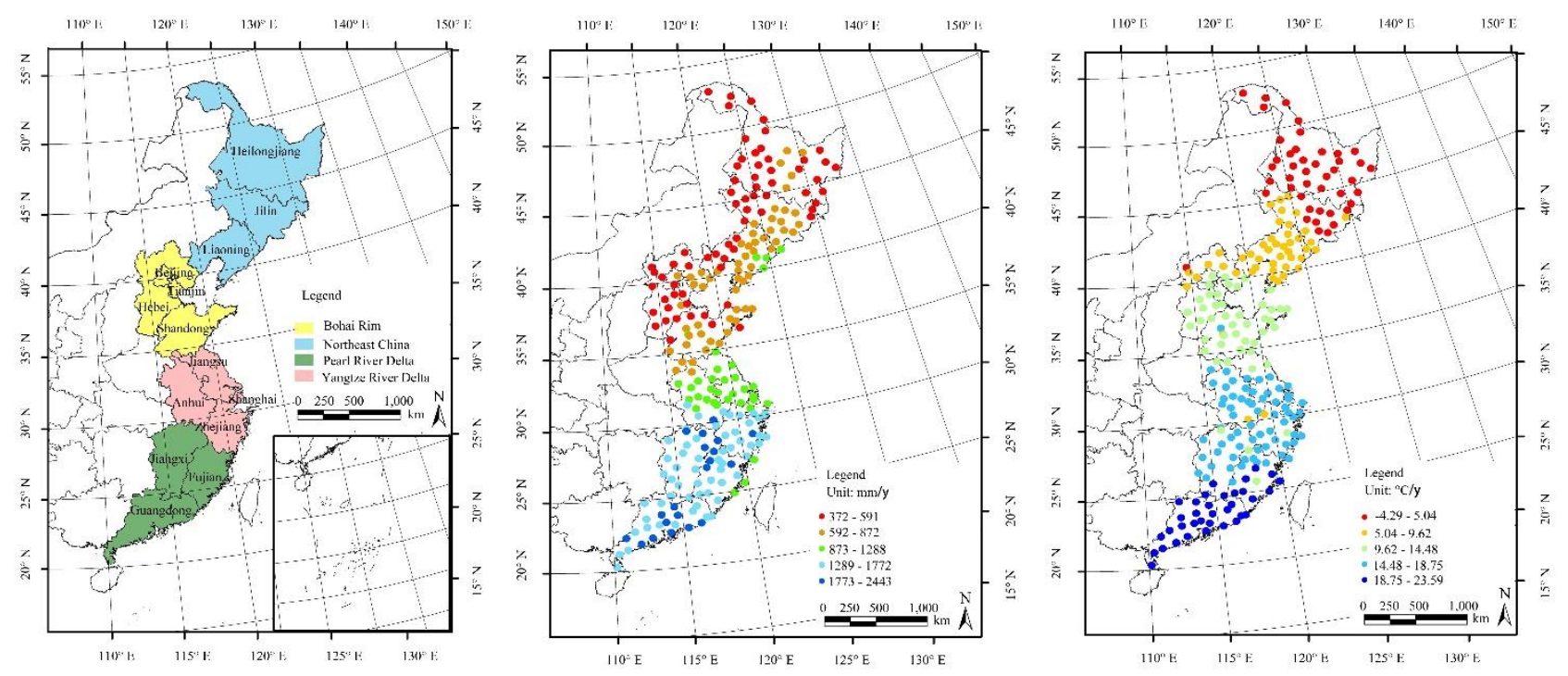

Figure 1. Location of study area in Eastern China. 
The density of vegetation coverage is high in the south and low in the north. From north to south, the natural vegetation types include boreal forest, temperate deciduous forest, temperate deciduous shrub, tropical and subtropical evergreen coniferous forests, subtropical evergreen broad-leaved forest, and tropical evergreen broad-leaved rainforest. The annual mean temperature for the study area was $13.81{ }^{\circ} \mathrm{C}$ in 1999 and $13.86{ }^{\circ} \mathrm{C}$ in 2008 , and the annual precipitation was $987.67 \mathrm{~mm}$ in 1999 and $1003.37 \mathrm{~mm}$ in 2008. There has been substantial and fast economic development in Eastern China. From 1999 to 2008, GDP increased to $\$ 3000$ billion from $\$ 700$ billion. The total human population increased to 0.68 billion from 0.62 billion and the urbanization rate increased to $58 \%$ from $37 \%$.

\subsection{Data Sources and Processing}

\subsubsection{NDVI Composite}

The initial NDVI time series may have singular values triggered by sensors and atmospheric factors, which present as sudden declines or humps. These singular values have effects on the accuracy of the NDVI time series and, thus, the NDVI needs to be processed to eliminate the negative effects. To eliminate the interference of cloud, atmosphere, sun elevation angle and other factors, Maximum Value Composites (MVC) was used to process NDVI time series using 10-day monthly composites, i.e., three 10-day composite images combined into a single month image. The calculation formula was as follows:

$$
N D V I_{i}=\max \left(N D V I_{i j}\right)
$$

where $N D V I_{i}$ was the NDVI of the $i$-th month, and $N D V I_{i j}$ was the NDVI of the $\mathrm{j}$-th 10 -days in the $i$-th month.

NDVI was obtained from the average of $N D V I_{i}$ of every month. As a result, the effects of extreme values could be avoided. The calculation formula was as follows:

$$
\overline{N D V I}=\frac{\sum N D V I_{i}}{n}
$$

where $\overline{N D V I}$ was the annual NDVI, $n$ was the number of months, and $N D V I_{i}$ was the NDVI of the $i$-th month.

In addition, the presence of noise due to cloud contamination, atmospheric variability, and bidirectional effects, can lead to highly volatile behavior on NDVI series [39]. Although the robustness of MVC method is widely accepted, some noises may exist in the compositing NDVI products [40,41]. The noisy effects of subpixel clouds, persistent cloudiness, snow, variable illumination, and viewing geometry tend to reduce the NDVI values and disturb the temporal profiles, thus affecting the algorithms that measure the vegetation dynamic [42]. Therefore, many smoothing algorithms have been applied to address this problem, such as Savitzky-Golay filter [43], Fourier series analysis [44], double logistic function [45], and asymmetric Gaussian function [46]. Among these algorithms, Harmonic Analysis of Time Series (HANTS), an improved fast Fourier transform (FFT) algorithm, is considered as a powerful tool to reproduce NDVI series [47]. Therefore, the HANTS algorithm is used to examine the difference between the raw NDVI and the smoothed one. The basic formula is written as [47]: 


$$
\begin{gathered}
\tilde{y}\left(t_{j}\right)=a_{0}+\sum_{i=1}^{n f}\left[a_{i} \cos \left(2 \pi f_{i} t_{j}\right)+b_{i} \sin 2 \pi f_{i} t_{j}\right] \\
y\left(t_{j}\right)=\tilde{y}\left(t_{j}\right)+\varepsilon\left(t_{j}\right)
\end{gathered}
$$

where $y, \tilde{y}$ and $\varepsilon$ are the original series, the reconstructed series, and the error series, respectively. $t_{j}$ is the time when $y$ is obtained, where $j=1,2, \ldots, \mathrm{n}$ with $\mathrm{n}$ as the maximum number of observations (samples) in a time series. $a_{i}$ and $b_{i}$ are the coefficients of the trigonometric components with frequencies $f_{i}$. $a_{0}$ can be viewed as the coefficient at zero frequency.

\subsubsection{Climate Data Selection}

To analyze the temporal correlation between NDVI and climate change, climate data and NDVI based on time series in meteorological stations were obtained. The yearly climate data set used in this study was generated from 752 meteorological stations with data available from 1951 onwards. Among these stations, 210 stations were finally selected that were distributed evenly in the study area; stations with incomplete data or extreme values were also eliminated. In this study, annual mean temperature and precipitation were used as climatic factors from 1999 to 2008.

In this paper, NDVI was extracted as follows: (i) buffer areas with a 10-km radius were set around each station to generate area vector data; and (ii) the mean NDVI in buffer areas was calculated by ArcGIS 10.2 as the NDVI at each meteorological station.

\subsubsection{DMSP/OLS Data Identification}

Describing the spatial characteristics of the urbanization process on a macroscale is the focus of urban geography and regional development studies. The Defense Meteorological Satellite Program (DMSP)/Operational Line-Scan System (OLS) nighttime stable light data (NTL) data for 1999-2008 was obtained from the National Geophysical Data Center at the National Oceanic and Atmospheric Administration [48]. Due to the relatively low pixel resolution and sensor signals with high interference, initial nighttime light data could not be directly used to extract urban spatial patterns.

Based on He et al. concerning spatial information relating to the urbanization process in Eastern China [49], in this study nighttime light data were processed as follows: (i) the binary image of DMSP/OLS was produced; (ii) a threshold was set in recursion for each province respectively, and then urban land-use patterns and the total urban area of each province were obtained; and (iii) the results above were compared with statistical data, until the total area of urban land derived from the DMSP/OLS threshold was sufficiently similar to the statistical data in China Statistical Yearbook. Thus, the spatial distribution of urban land in 1999 and 2008 in Eastern China was obtained. The extracted area was compared with statistical data to calculate the area error and to evaluate precision (Table 1), which was found to be acceptable. Furthermore, one of the basic characteristics of urbanization in Eastern China is that mean light DN values of the true urban pixels do not decrease. According to this feature, we hypothesized that during the study period, the characteristics of the urban areas did not change, whereas those of the rural areas changed. The areas that changed from rural areas to urban areas were defined as the urban extending areas. Based on this assumption, spatial information of the urban extending areas 
from 1999 to 2008 was obtained by overlaying the images of 1999 and 2008 . Figure 2 showed the spatial pattern of urbanization on the timeline.

Table 1. Accuracy assessment of urban area extraction using DMSP/OLS in 1999 and 2008.

\begin{tabular}{|c|c|c|c|c|c|c|}
\hline & & 1999 & & & 2008 & \\
\hline Province & Threshold & $\begin{array}{c}\text { Area } \\
\text { Extracted } \\
\left(\mathbf{k m}^{2}\right)\end{array}$ & $\begin{array}{c}\text { Error } \\
\text { Percentage } \\
(\%)\end{array}$ & Threshold & $\begin{array}{c}\text { Area } \\
\text { Extracted } \\
\left(\mathbf{k m}^{2}\right)\end{array}$ & $\begin{array}{c}\text { Error } \\
\text { Percentage } \\
(\%)\end{array}$ \\
\hline Heilongjiang & 8 & 14,789 & 2.83 & 16 & 15,136 & 1.74 \\
\hline Jilin & 6 & 8,887 & -13.94 & 11 & 10,325 & -2.97 \\
\hline Liaoning & 8 & 13,590 & 4.06 & 16 & 14,158 & 1.30 \\
\hline Hebei & 10 & 17,130 & 3.85 & 19 & 18,058 & 0.82 \\
\hline Beijing & 36 & 2,651 & 0.45 & 55 & 3,336 & -1.07 \\
\hline Tianjin & 19 & 3,045 & 0.98 & 37 & 3,699 & 0.76 \\
\hline Shandong & 8 & 23,755 & 7.15 & 19 & 25,493 & 1.62 \\
\hline Jiangsu & 10 & 15,614 & -4.51 & 34 & 19,436 & 1.00 \\
\hline Shanghai & 47 & 2,098 & -1.29 & 58 & 2,785 & 10.34 \\
\hline Zhejiang & 14 & 7,475 & -2.47 & 37 & 10,412 & 0.08 \\
\hline Fujian & 14 & 5,275 & 0.07 & 27 & 6,371 & -1.20 \\
\hline Guangdong & 22 & 15,225 & -0.56 & 38 & 17,966 & 0.46 \\
\hline Anhui & 4 & 15,444 & -1.98 & 10 & 15,778 & -5.01 \\
\hline Jiangxi & 4 & 8,289 & -2.84 & 10 & 9,141 & -3.73 \\
\hline
\end{tabular}

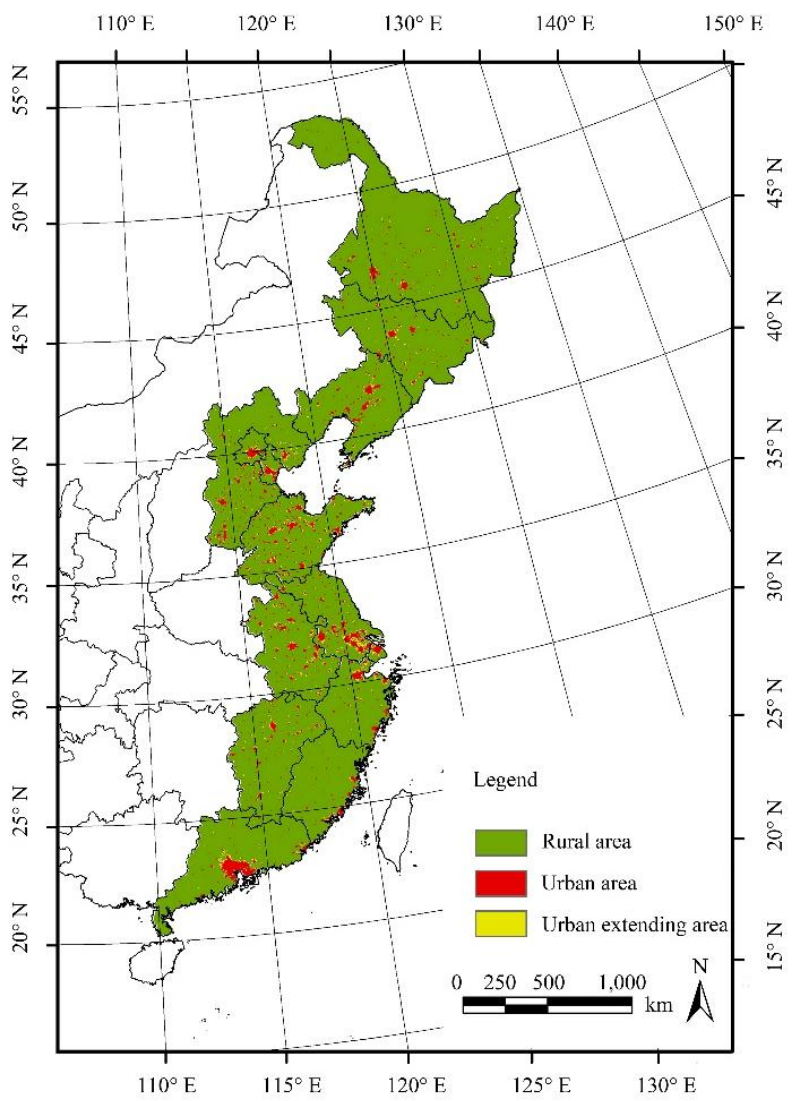

Figure 2. Distribution of urban expansion in Eastern China from 1999 to 2008. 


\subsection{Trend Analysis of Vegetation Dynamics}

It is an important method in vegetation change trend analysis to carry out a regression analysis of time-varying variables and to predict their trends [17,50-53]. The slope of the equation developed using linear least square fitting of long time NDVI series shows NDVI trends over several years. [17,53]. Simple linear regression can investigate the relation between two linear-related variables, which is usually used in remote sensing analysis of NDVI from long time series. In a trend analysis of vegetation dynamics, Slope was viewed as the slope of the regression equation. If Slope is positive, vegetation dynamics showed a rising trend, and vice versa. Therefore, the tendency of vegetation dynamics can be judged from Slope value. Then the NDVI change contrast between urbanized and non-urbanized areas, the urban and rural grids were identified in 1999 and 2008, respectively, resulting in four groups of statistical samples. Furthermore, a non-parametric slope is derived from the Theil-Sen procedure, which has been used in vegetation dynamic analysis due to its robustness against seasonality and non-normality [24,38,50]. The comparison between the results of the Theil-Sen procedure and simple linear regression can be effective in showing whether the validity of normality assumptions for data variables in linear regression can influence the results.

\subsection{Partial Correlation Analysis of Driving Forces}

Correlation analysis is considered as a common methodology of analyzing the relations between vegetation dynamics and associated driving factors. The closer the correlation coefficient to one, the higher the linear correlation is. When the correlation coefficient equals zero, there is no linear correlation among variables. However, due to the correlation among various factors, what the simple correlation coefficient reveals are not the essential relations among variables. To reflect the internal relation between two variables, a partial correlation coefficient is needed. Partial correlation coefficients reveal the linear relation of two variables when controlling the impact of other variables. Specifically, when two variables are both related to the third, only the linear relation between the former two variables is analyzed with the impact of the third variable eliminated [54]. Therefore, partial correlation analysis is used to separate the driving forces of temperature and precipitation on vegetation dynamics.

\section{Result}

\subsection{Trends in NDVI Change}

As shown in Table 2 and Figure 3, during the study period, the NDVI in Eastern China increased significantly $(p=0.017)$, with a slope of 0.0032 , and the NDVI value increased significantly during 2005-2007. Since the increase and decrease trends can be offset, the coefficient of variation (CV) of 0.031 and standard deviation (S) of 0.014 were both the lowest. The increase of NDVI in the Yangtze River Delta, with a slope of 0.0066 , was the most significant in the four sub-regions $(p=0.000)$. The $S$ of 0.021 and the CV of 0.041 were both the highest. A high slope of 0.0049 was found in Northeast China, but the change was not significant $(p=0.079)$. The $\mathrm{CV}$ of 0.039 was as high as the CV in the Bohai Rim, where the slope of 0.0031 had passed the significance test $(p=0.034)$. In the Pearl River Delta, the slope was only 0.0029 and did not pass the significance test $(p=0.082)$. Although the CV of 
0.032 was low, the $S$ of 0.019 was relatively high. The $S$ and the CV represented the magnitudes of NDVI fluctuation. A high magnitude could either describe the large difference of NDVI value between start and end, which resulted in a high slope, or describe the large fluctuation of NDVI in the middle years which might not result in a high slope. Therefore the relationships between slope and S/CV were not unique. In the result in Figure 3, a high CV often corresponded to a high slope, but a high S could not refer to that. There was neither correlation between $p$ and CV nor between $p$ and S. These correlations cannot be replaced by each other.

Table 2. Trends of annual NDVI changes in Eastern China during 1999-2008.

\begin{tabular}{ccc}
\hline Region & Fitting Equation & $\boldsymbol{p}$ Value \\
\hline Eastern China & $\mathrm{y}=0.0032 \mathrm{x}-5.031$ & 0.017 \\
Northeast China & $\mathrm{y}=0.0049 \mathrm{x}-4.908$ & 0.079 \\
Bohai Rim & $\mathrm{y}=0.0031 \mathrm{x}-6.167$ & 0.034 \\
Yangtze River Delta & $\mathrm{y}=0.0066 \mathrm{x}-12.627$ & 0.000 \\
Pearl River Delta & $\mathrm{y}=0.0029 \mathrm{x}-6.209$ & 0.082 \\
\hline
\end{tabular}
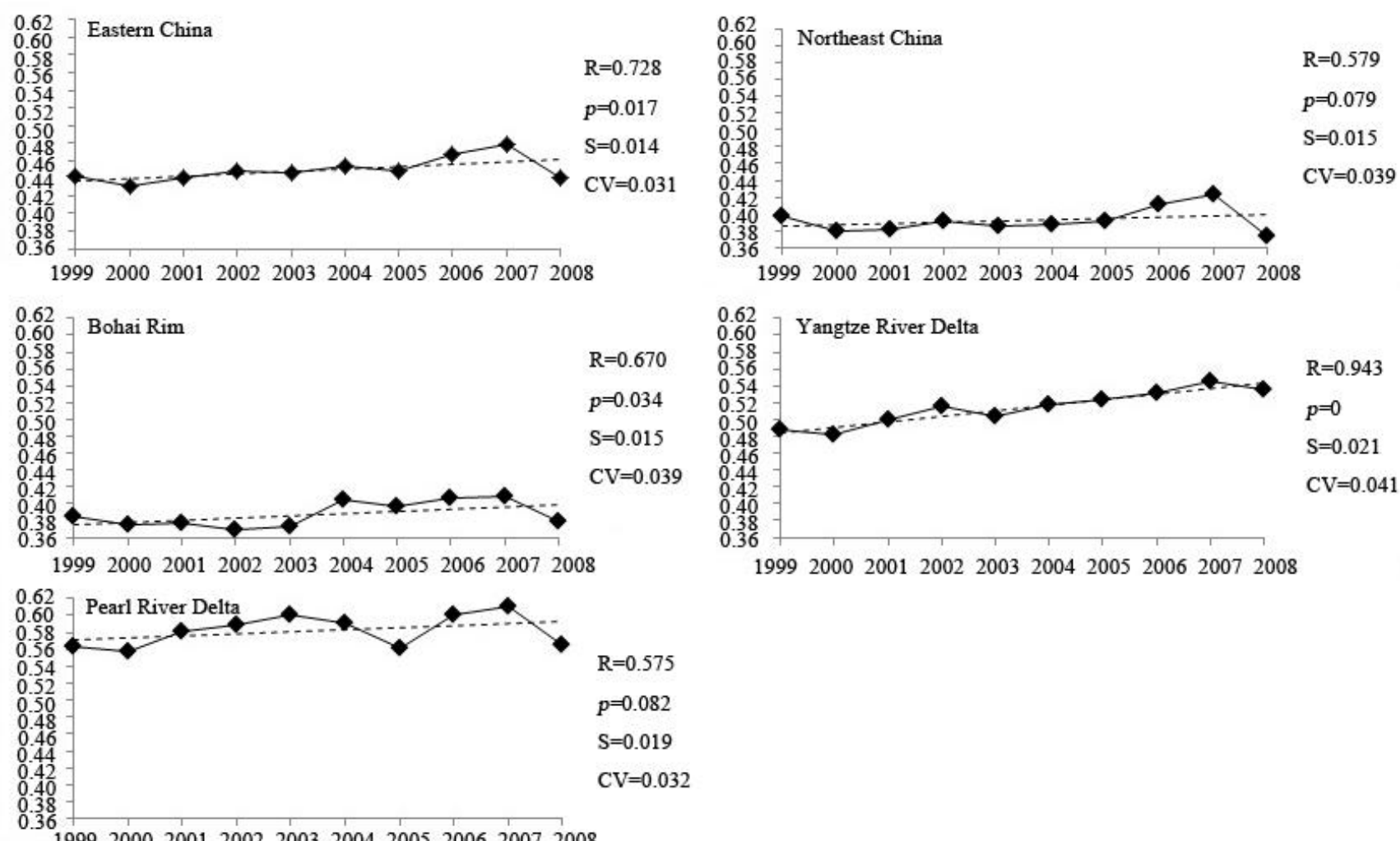

1999200020012002200320042005200620072008

1999200020012002200320042005200620072008

Figure 3. Trends of annual NDVI changes in Eastern China during 1999-2008, where R is the Pearson correlation coefficient; $p$ is the significance level; $\mathrm{S}$ is the Standard deviation; and $\mathrm{CV}$ is the variable coefficient; sample size (n) is 10 .

According to the distribution of the slope of NDVI change (Figure 4), there were two kinds of areas, where the slope was either negative or positive. In the former areas with vegetation degradation, there were two distribution forms: (i) even planar distribution. In these areas, the absolute value of the slope was small, including the west and south of Northeast China, the outer margin of the Bohai Rim, and the 
Pearl River Delta, especially Guangxi and Jiangxi; and (ii) centralized block distribution. In these areas, the absolute value of the slope was large, including Beijing, Tianjin, the entrance to the Yangtze River Delta, especially Shanghai, and the entrance to the Pearl River Delta. In the latter areas with increasing vegetation, the distribution was mainly planar. It was distributed widely in the study area, of which the areas with large slope were located mainly in the north of Northeast China and the Yangtze River Delta, especially in the north of Shandong, Jiangsu, and Anhui.

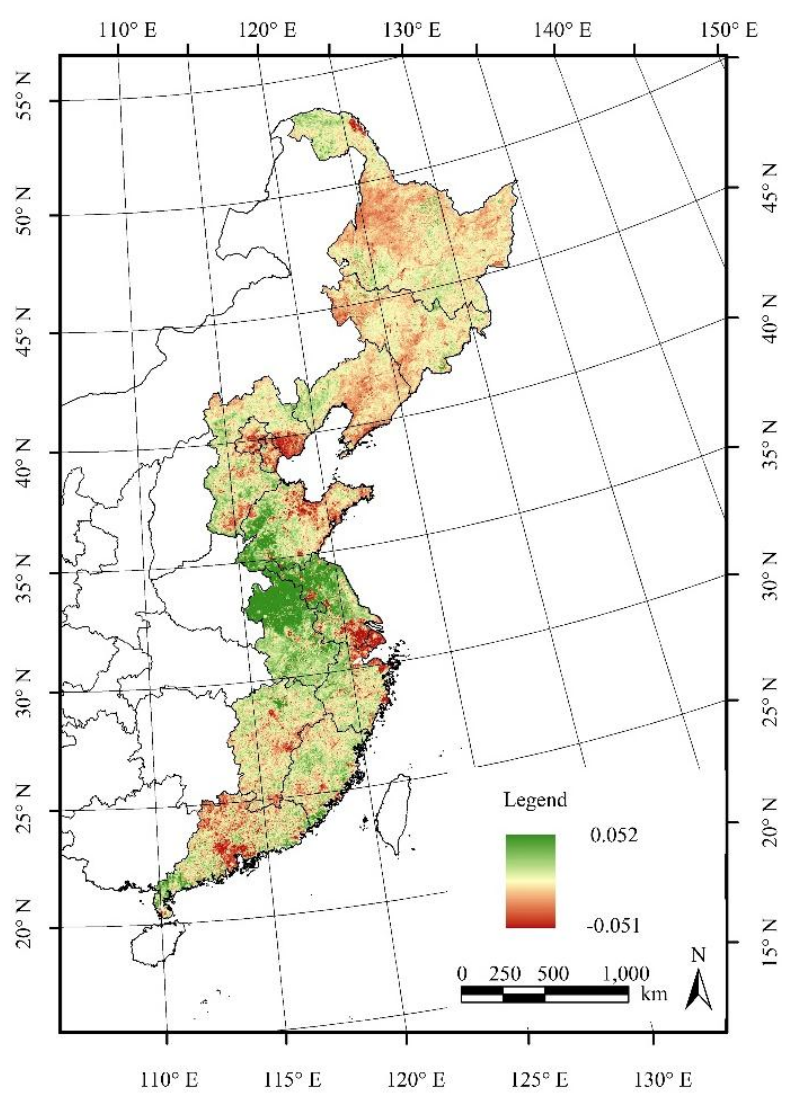

Figure 4. Vegetation change trends in Eastern China during 1999-2008.

\subsection{Vegetation Change and Climatic Factors}

The partial correlation coefficients of NDVI and temperature/precipitation were obtained, respectively, using the data of annual temperature and precipitation from 210 selected meteorological stations. The significance level of partial correlation analysis and the distribution pattern of partial correlation coefficients were also obtained. Therefore, the driving forces of temperature and precipitation on NDVI were reflected. To be specific, the partial correlation coefficients can reflect the relationship between NDVI and temperature/precipitation. Then, the primary climatic driving factor was determined with the highest partial correlation coefficient. The spatial distribution of the partial correlation coefficients can reflect the spatial variations of driving effects of climatic factors on the NDVI change.

As shown in Figure 5 and Table 3, the partial correlation coefficients of NDVI and temperature were $>-0.7$ and $<0.9$. In terms of the spatial distribution, within 210 meteorological stations, 153 stations reported a positive correlation between NDVI and temperature. In Northeast China, the Bohai Rim, and the Pearl River Delta, there was a positive correlation between NDVI and temperature in more 
than $70 \%$ of the stations, but only $46.67 \%$ of the stations reported a positive correlation in the Yangtze River Delta. There were more meteorological stations reporting a positive correlation between temperature and NDVI than were reporting a negative correlation. Specifically, the former were distributed mainly in the south of Northeast China, as well as the south and southeast coastal areas of the Bohai Rim. The latter were distributed mainly in the center of the Bohai Rim, the Yangtze River Delta, and the northwest of the Pearl River Delta.

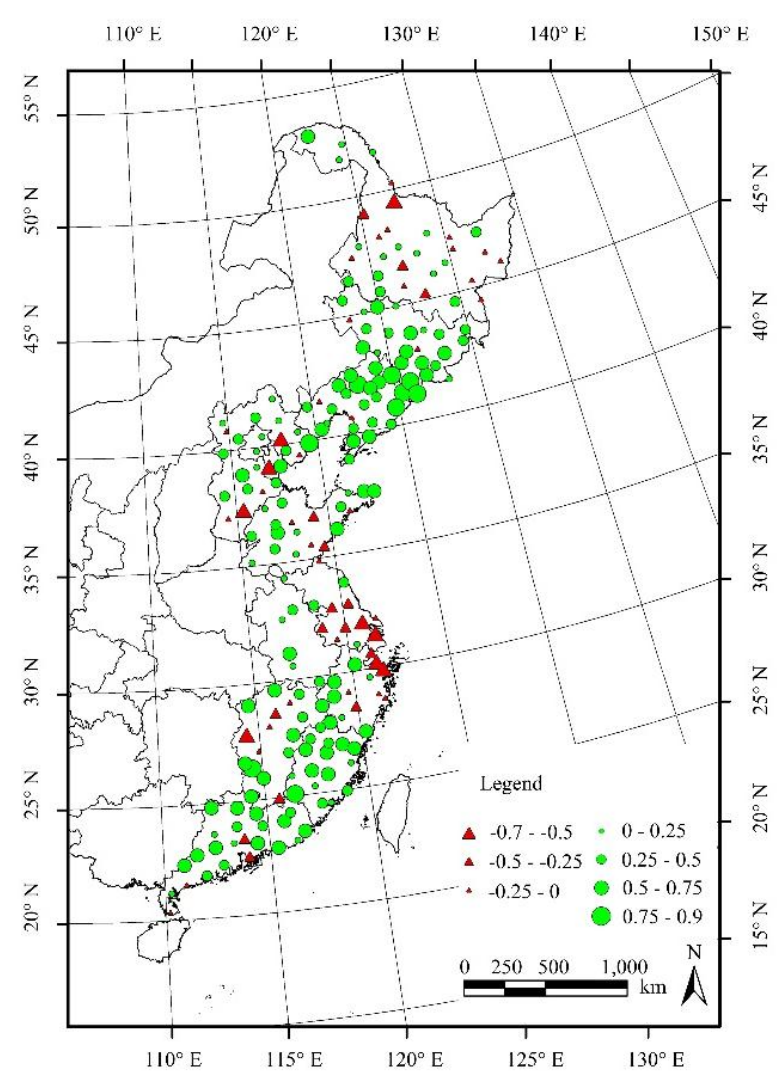

Figure 5. Spatial patterns of partial correlation coefficients between NDVI and temperature of meteorological stations in Eastern China.

Table 3. Partial correlation coefficients between NDVI and temperature of meteorological stations in Eastern China.

\begin{tabular}{ccccccc}
\hline \multirow{2}{*}{ Region } & \multicolumn{2}{c}{ Negative Correlation } & \multicolumn{2}{c}{ Positive Correlation } & \multicolumn{2}{c}{ Sum } \\
\cline { 2 - 6 } & No. & \% & No. & \% & No. & \% \\
\hline Eastern China & 57 & 27.14 & 153 & 72.86 & 210 & 100 \\
Northeast China & 19 & 24.05 & 60 & 75.95 & 79 & 100 \\
Bohai Rim & 12 & 27.91 & 31 & 72.09 & 43 & 100 \\
Yangtze River Delta & 16 & 53.33 & 14 & 46.67 & 30 & 100 \\
Pearl River Delta & 10 & 17.24 & 48 & 82.76 & 58 & 100 \\
\hline
\end{tabular}

By looking at Figure 6 and Table 4, it can be seen that the partial correlation of NDVI and precipitation was $>-0.9$ and $<0.9$. In terms of the spatial distribution, within 210 meteorological stations, 110 stations reported a positive correlation between NDVI and precipitation, and 100 stations reported a negative correlation between NDVI and precipitation. Apparently, the amount of the two 
kinds of stations are almost equal to each other. In Northeast China, the Bohai Rim, and the Pearl River Delta, more than $50 \%$ of the stations reported a negative correlation between precipitation and NDVI. However, in the Yangtze River Delta, $80 \%$ of the stations reported a positive correlation between precipitation and NDVI. On the whole, the amount of stations reporting a positive correlation was slightly more than those reporting a negative correlation. Specifically, the former stations were mainly distributed in the coastal area of the Yangtze River Delta, and the inland of the other sub-regions.

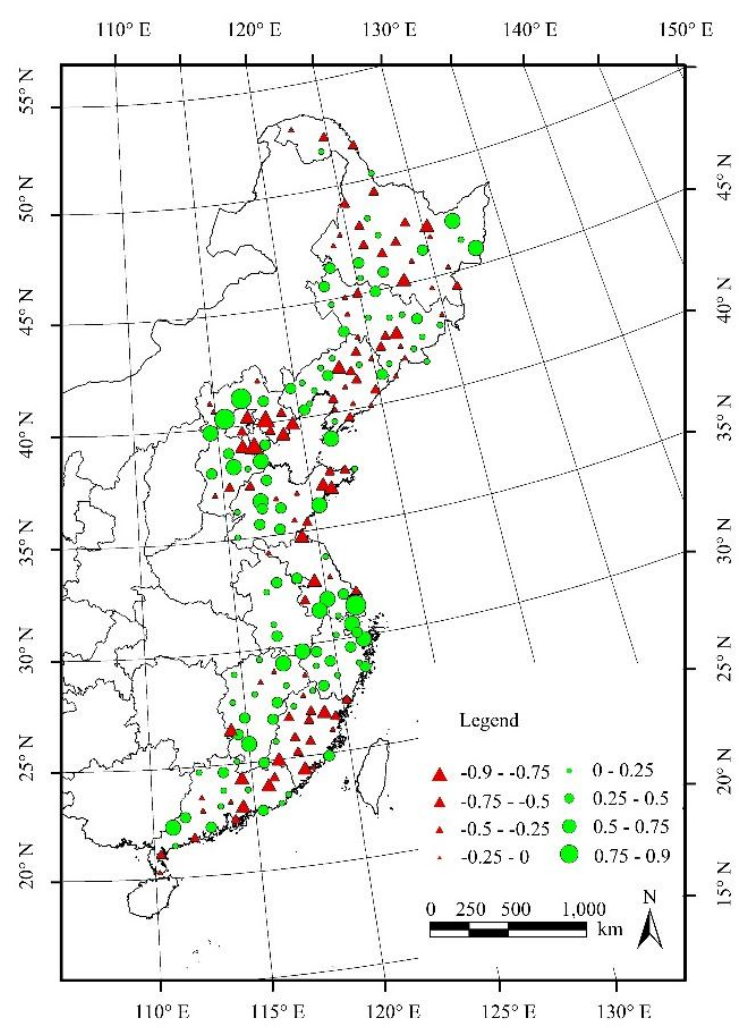

Figure 6. Spatial patterns of partial correlation coefficients between NDVI and precipitation of meteorological stations in Eastern China.

Table 4. Partial correlation coefficients between NDVI and precipitation of meteorological stations in Eastern China.

\begin{tabular}{ccccccc}
\hline \multirow{2}{*}{ Region } & \multicolumn{2}{c}{ Negative Correlation } & Positive Correlation & \multicolumn{2}{c}{ Sum } \\
\cline { 2 - 6 } & No. & \% & No. & \% & No. & $\%$ \\
\hline Eastern China & 100 & 47.62 & 110 & 52.38 & 210 & 100 \\
Northeast China & 42 & 53.16 & 37 & 46.84 & 79 & 100 \\
Bohai Rim & 23 & 53.49 & 20 & 46.51 & 43 & 100 \\
Yangtze River Delta & 6 & 20 & 24 & 80 & 30 & 100 \\
Pearl River Delta & 29 & 50 & 29 & 50 & 58 & 100 \\
\hline
\end{tabular}

The impact of the two climatic factors on vegetation activities was judged by the absolute value of the partial correlation coefficients between NDVI and temperature/precipitation. For one meteorological station, the climatic factor with the bigger absolute value was regarded as the primary climatic driving factor of NDVI change. In Eastern China, the primary climatic driving factor was temperature in 120 stations, accounting for $57.14 \%$ of the total, and it was precipitation in 90 stations, accounting for $42.86 \%$ 
of the total (Figure 7 and Table 5). In terms of the spatial distribution, in Northeast China, the primary climatic driving factor was temperature in more than $60 \%$ of the stations, and in the rest $39.24 \%$ of the stations precipitation was the driving factor; in the Bohai Rim, the primary climatic driving factor was precipitation in $67.44 \%$ of the stations, and it was temperature in $32.56 \%$ of the stations; in the Yangtze River, the primary climatic driving factor was precipitation in $60 \%$ of the stations, and it was temperature in $40 \%$ of the stations; in the Pearl River Delta, the primary climatic driving factor was temperature in $79.31 \%$ of the stations, and it was precipitation in $20.69 \%$ of the stations. Thus, the spatial distribution of primary climatic driving factors in Eastern China can be characterized as follows: annual NDVI change was mainly dominated by temperature in Northeast China and Pearl River Delta, as well as Bohai Rim for precipitation; while in the Yangtze River Delta, both temperature and precipitation were equally dominant predictors of vegetation dynamics.

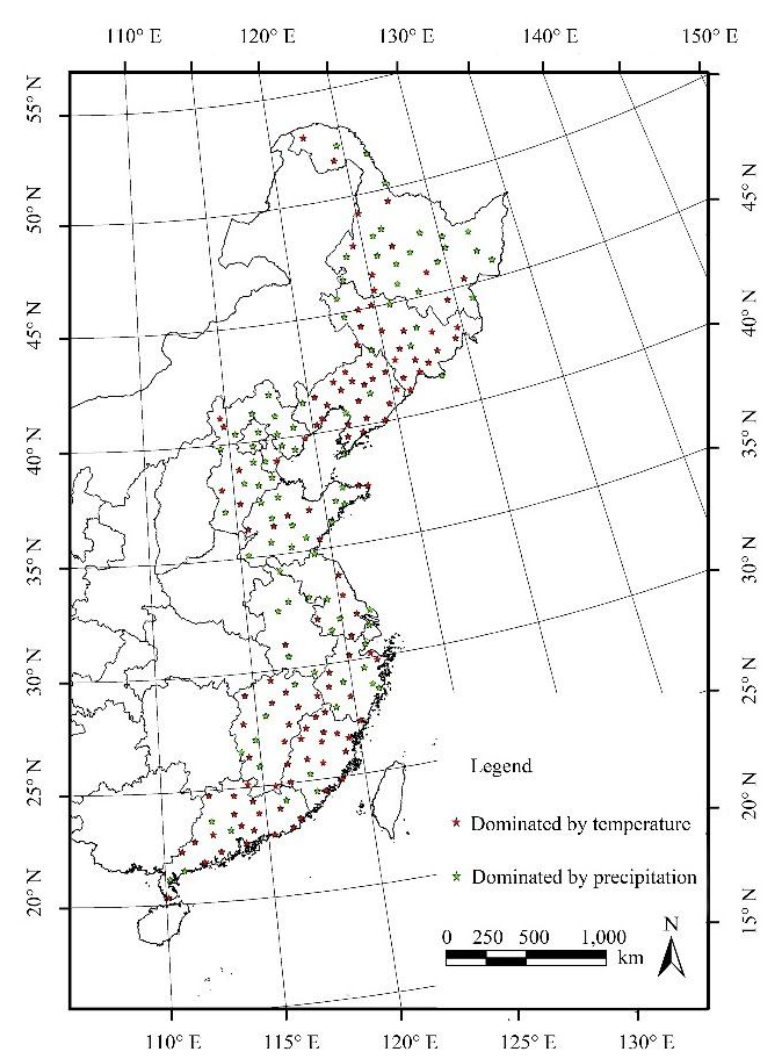

Figure 7. The primary climatic driving factors of vegetation change of meteorological stations in Eastern China.

Table 5. The primary climatic driving factors of vegetation change of meteorological stations in Eastern China.

\begin{tabular}{ccccccc}
\hline \multirow{2}{*}{ Region } & \multicolumn{2}{c}{ Temperature Dominated } & \multicolumn{2}{c}{ Precipitation Dominated } & \multicolumn{2}{c}{ Sum } \\
\cline { 2 - 7 } & No. & \% & No. & \% & No. & $\%$ \\
\hline Eastern China & 120 & 57.14 & 90 & 42.86 & 210 & 100 \\
Northeast China & 48 & 60.76 & 31 & 39.24 & 79 & 100 \\
Bohai Rim & 14 & 32.56 & 29 & 67.44 & 43 & 100 \\
Yangtze River Delta & 12 & 40 & 18 & 60 & 30 & 100 \\
Pearl River Delta & 46 & 79.31 & 12 & 20.69 & 58 & 100 \\
\hline
\end{tabular}




\subsection{Vegetation Change in Urban and Rural Areas}

The urbanization process is regarded as the macroscopic manifestation of anthropogenic activities during a certain period of time. Over the past 10 years, there was large-scale urbanization processes in Eastern China [55,56], which made it possible to study the impact of anthropogenic factors on vegetation activities on a large scale in this region. Variations of the vegetation activities between urban and rural areas have received much attention from researchers [57-59]. However, many studies have focused on the spatial impact of urbanization on vegetation while ignoring the temporal impact of urbanization on vegetation. In this study, the change of urbanization processes on the timeline was used to characterize the impact of urbanization on vegetation density.

Figure 8a showed the mean NDVI of urban versus rural areas in 1999 and 2008. In 1999, the mean NDVI of urban areas in Eastern China was 0.3585, and it was 0.4481 in rural areas. The difference in mean NDVI between the urban and rural areas were the largest in the Pearl River Delta and Yangtze River Delta, being 0.222 and 0.136, respectively. The differences were 0.089 in Northeast China and 0.058 in Bohai Rim. In the urban areas, the mean NDVI of the Yangtze River Delta was the highest, which of Northeast China was the lowest; in the rural areas, the mean NDVI of the Pearl River Delta was the highest, and that of Bohai Rim was the lowest. In 2008, the mean NDVI of urban areas in Eastern China was 0.3293, and of rural areas was 0.4467. The mean NDVI difference between the urban and rural areas of Pearl River Delta and Yangtze River Delta was the largest, which was 0.221 and 0.133, respectively. The difference was 0.088 in Northeast China and 0.059 in Bohai Rim. In the urban areas, the mean NDVI in Yangtze River Delta was the highest, and it was the lowest in Northeast China; in the rural areas, the mean NDVI of Pearl River Delta was the highest, with the lowest in Bohai Rim. On the whole, the mean NDVI of the urban areas was lower than those of the rural areas. This suggested that urban areas containing more anthropogenic activities had a negative effect on vegetation density, manifesting as the decrease in mean NDVI. There were spatial variations in mean NDVI of urban and rural areas, with high mean NDVI in Pearl River Delta and Yangtze River Delta, and low mean NDVI in Northeast China and Bohai Rim. Meanwhile, the difference of mean NDVI between the urban and rural areas also showed a spatial variation, being higher mainly in Pearl River Delta and Yangtze River Delta. This might be either because the primary NDVI was lower in the north, but higher in the south (especially in Yangtze River Delta and Pearl River Delta), or because there was stronger urbanization in the south over the past 10 years.

The slope of NDVI change in the urban and rural areas during 1999-2008 was shown in Figure 8b. For the urban and rural areas identified in 1999, the slope was -0.001 in the urban areas and 0.003 in the rural areas, which suggested that vegetation density decreased in the urban areas, but increased in the rural areas. To be specific, in the urban areas, the slope of NDVI change was negative in Northeast China, Bohai Rim, and Pearl River Delta, and it was the minimum in Pearl River Delta. However, the slope was positive in Yangtze River Delta but near 0. In the rural areas, the slope was positive in four sub-regions, and it was the maximum in Yangtze River Delta. In terms of the slope variation between the urban and rural areas, it was the maximum in Yangtze River Delta, followed by Pearl River Delta, Bohai Rim, and Northeast China. For the urban and rural areas identified in 2008, the slope was -0.002 in the urban areas and 0.003 in the rural areas, which also suggested that the vegetation density decreased in the urban areas, but increased in the rural areas. In the urban areas, the slope was negative in four 
sub-regions, and it was the maximum absolute value in Pearl River Delta. In the rural areas, the slope was positive in four sub-regions, and it was the maximum in Yangtze River Delta. In terms of the slope variation between the urban and rural areas, it was the maximum in Yangtze River Delta, followed by Pearl River Delta, Bohai Rim, and Northeast China. On the whole, the absolute value of vegetation change slope was lower in the urban areas than in the rural areas. Although there exists the same trend of slope in the urban and rural areas in some region, the slope of the urban areas was lower. Therefore, it can be concluded that anthropogenic activities influenced the trends in vegetation density directly. In the areas where anthropogenic activities were strong, vegetation density decreased and vice versa. There were spatial variations in the trends of vegetation change between the urban and rural areas. In the urban areas, the trends were high in the south and low in the north; in the rural areas, the trends were higher in the Yangtze River Delta than in other sub-regions. Furthermore, the difference of vegetation change slopes between the urban and rural areas also showed spatial variations, being higher in the south (Yangtze River Delta and Pearl River Delta). This might result from the variations of anthropogenic activity intensity in the south versus the north, or the different patterns in climate change in the south versus the north.

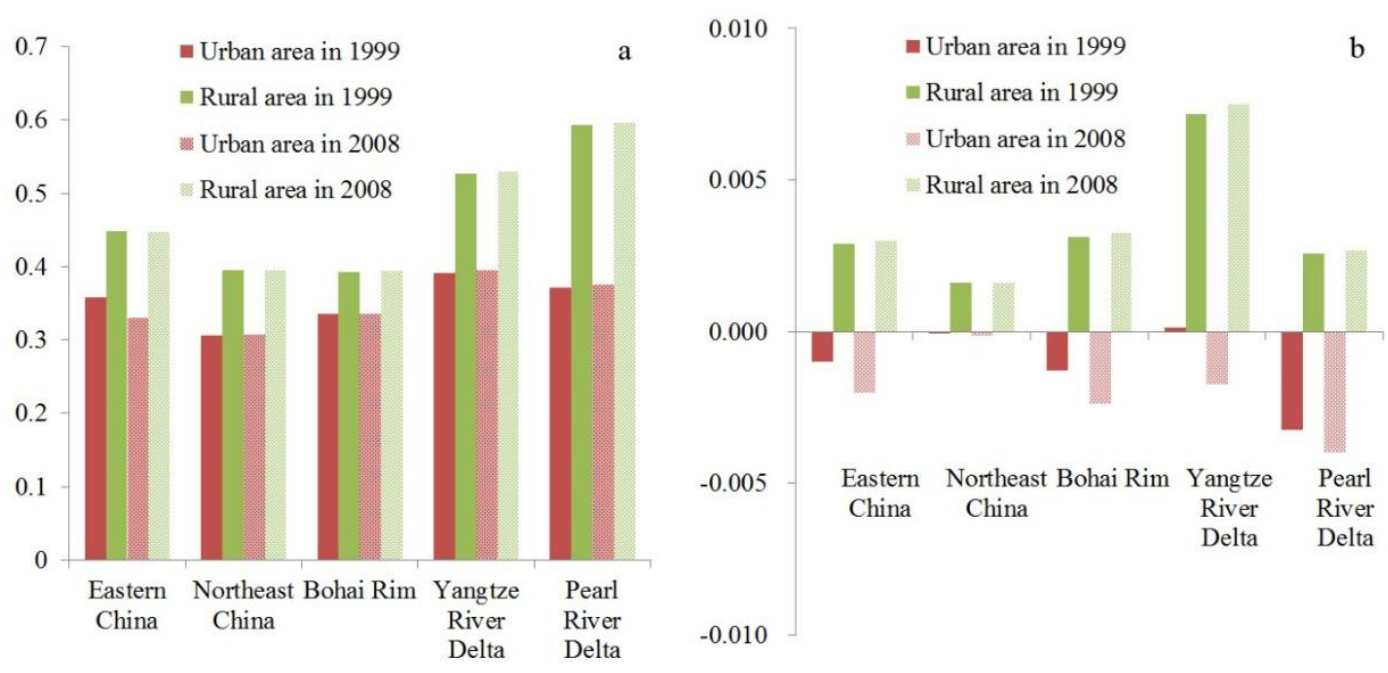

Figure 8. NDVI change of the urban and rural areas in Eastern China in 1999 and 2008. (a) Mean NDVI; and (b) slope of NDVI change trend.

\section{Discussion}

\subsection{Effects of Urbanization on NDVI}

Urbanization is a typical anthropogenic activity. During the study period, the mean NDVI was 0.3970 in the urban extending areas, 0.3439 in the urban areas, and 0.4474 in the rural areas (Figure 9a). In the urban extending areas, the mean NDVI of Yangtze River Delta was the highest, which of Northeast China was the lowest. In the urban areas, the mean NDVI of Yangtze River Delta was the highest, and that of Northeast China was the lowest. In the rural areas, the mean NDVI of Pearl River Delta was the highest, and that of Bohai Rim was the lowest. The differences of mean NDVI between the urban extending areas and the urban areas or the rural areas showed spatial variations. The largest difference 
between the urban extending areas and the rural areas was in Pearl River Delta, followed by Yangtze River Delta, Northeast China, and Bohai Rim, with the same order for the difference between the urban extending areas and the urban areas. On the whole, the mean NDVI in the urban extending areas was stronger than in the urban areas, but weaker than in the rural areas. This suggested that the intensity of anthropogenic activities influenced the vegetation density directly. Meanwhile, compared with the urban areas, the urban extending areas have a shorter construction history, and the negative effects of anthropogenic activities on vegetation density are unlikely to mirror those in fully-urbanized areas. Therefore, it can be concluded that anthropogenic activities have a cumulative effect across the time series.

During the study period, the slope of vegetation change in the urban extending areas in Eastern China was -0.002 , with -0.001 and 0.003 for the urban areas and the rural areas, respectively (Figure $9 \mathrm{~b}$ ). In the urban extending areas, although the slope of the vegetation change trend in Northeast China was positive, it was negative in the rest of the sub-regions, showing a descending order of Yangtze River Delta, Bohai Rim, and Pearl River Delta. In addition, the difference of vegetation change slope between the urban areas and the urban extending areas showed spatial variations. The largest was in Yangtze River Delta, followed by Bohai Rim, Pearl River Delta, and Northeast China. However, for spatial variation of the difference of vegetation change slope between the rural areas and the urban extending areas, the descending order was from Yangtze River Delta to Pearl River Delta, Bohai Rim, and Northeast China. As a whole, the slope of vegetation change in the urban extending areas was negative, which suggested that anthropogenic activities led to a weakening of vegetation density. In addition, the slope of vegetation change in the urban extending areas was smaller than that in the urban areas, which indicated the effects of anthropogenic activities on vegetation density was larger in the urban extending areas. During the process of urbanization, the effects of anthropogenic activities on vegetation change varied at different stages. To be specific, in the urban expansion stage, anthropogenic activities caused a significant reducing in vegetation density, but once anthropogenic activities in the urban areas plateaued, the decreasing of the vegetation density would slow down and might even begin reversing.
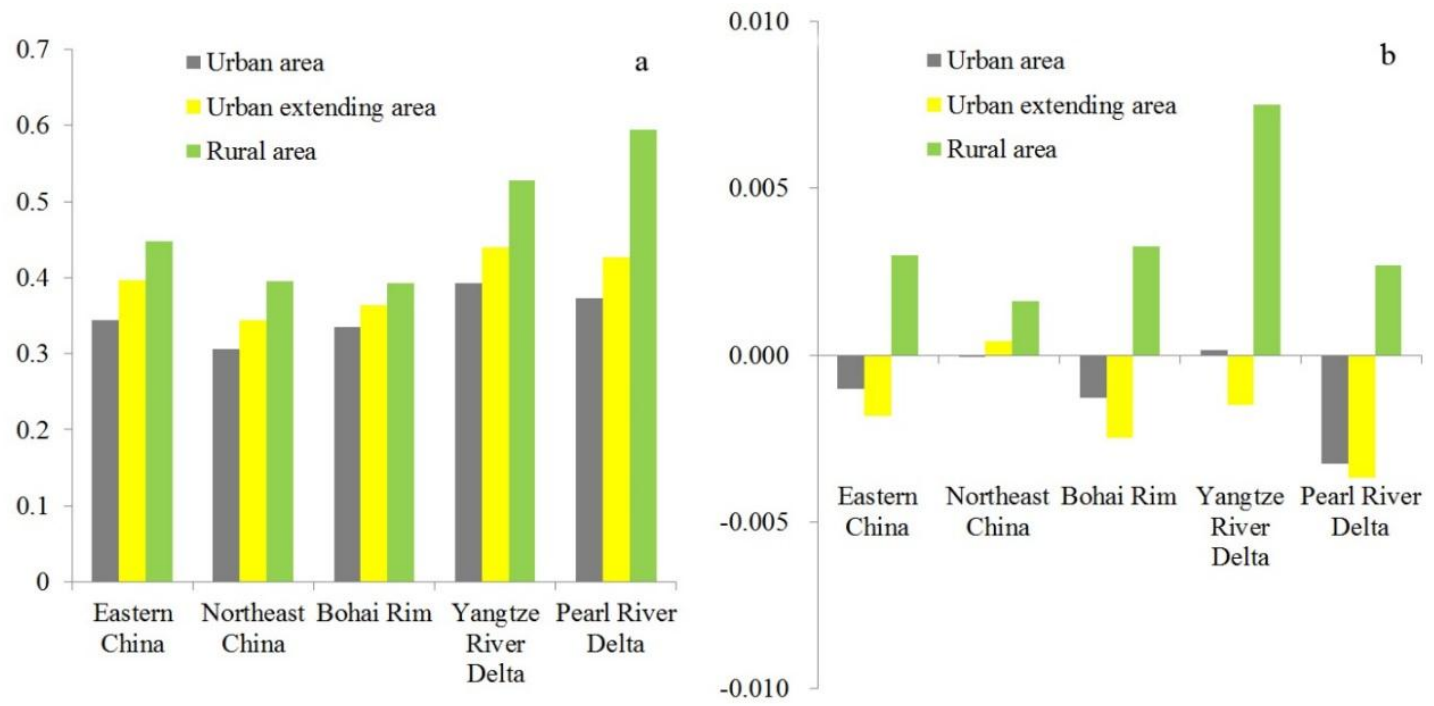

Figure 9. NDVI change of the urban areas, rural areas, and urban extending areas in Eastern China during 1999-2008. (a) Mean NDVI; and (b) slope of NDVI change trend. 


\subsection{Method Comparison}

To compare vegetation change trends resulted from the raw NDVI and smoothed one, four random points with different land use types were selected to extract the sample NDVI series (Figure 10). For the sample points of broadleaf deciduous trees and grass, as shown in Figure 10a,d, noise had been removed without a large change of data range. In contrast, the data ranges had been largely shrunk for crops and needle leaf evergreen trees, indicating the NDVI series in some regions might be different after smoothing. This was particularly true for the case shown in Figure 10c, where the data quality was greatly improved, as we know that the great vibration for needle leaf evergreen trees shown in the raw data was most unlikely to occur. Unlike Figure 10c where low values had been eliminated, some high NDVI values of crops in Figure $10 \mathrm{~b}$ had been treated as noisy pixels. Since the actual vegetation growth should not be an oscillation curve in one year, it could be found that data smoothing would reduce the noise and, thus, make the distinct change of data series for certain land cover types at the pixel scale, although it was still unknown whether there were substantial damages to the characterizing of real vegetation growth in the process of noise removing.

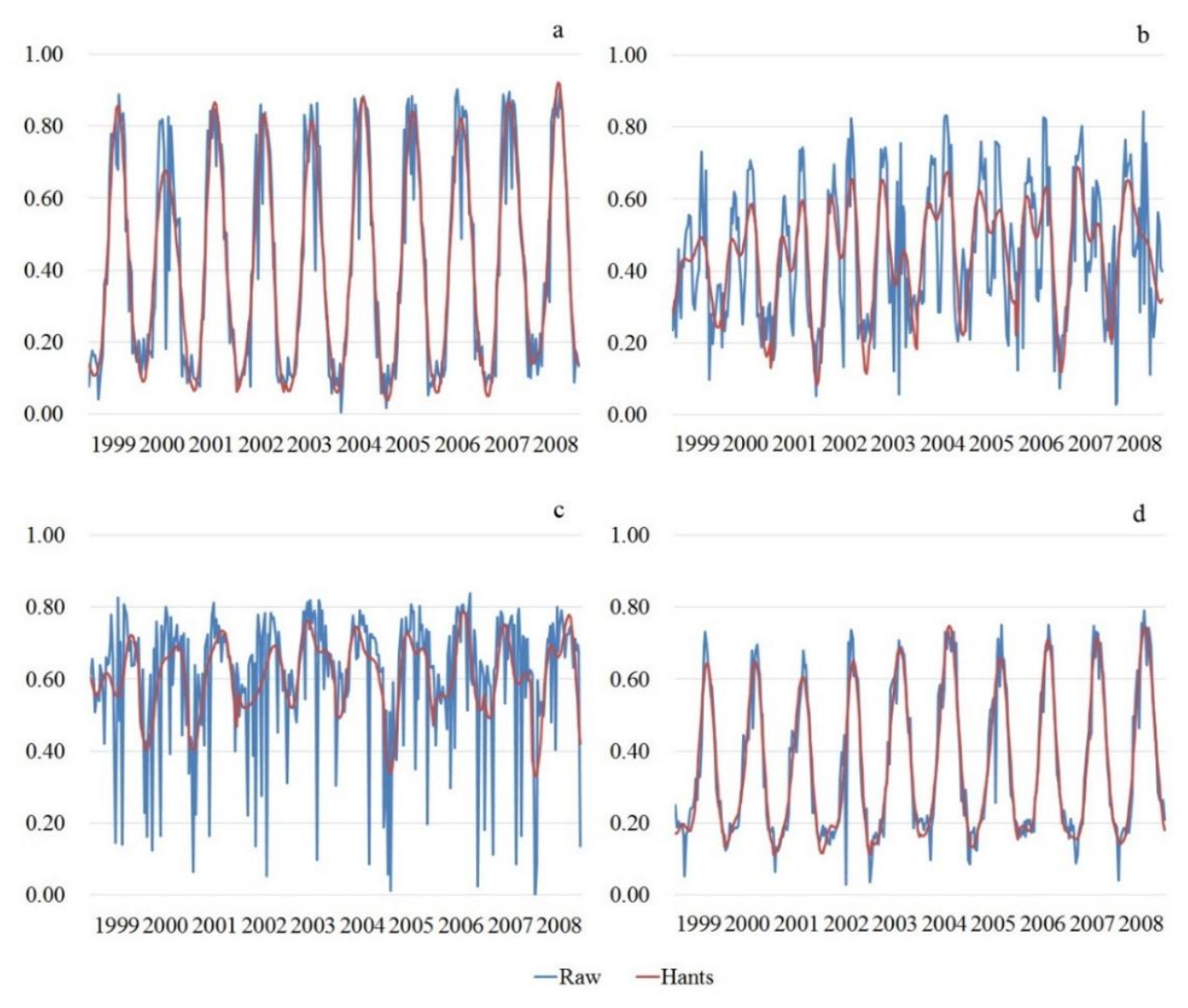

Figure 10. Comparison of raw NDVI and HANTS-filtered NDVI. (a) Broadleaf deciduous tree, $129^{\circ} 08^{\prime} 56^{\prime \prime} \mathrm{E}, 45^{\circ} 16^{\prime} 44^{\prime \prime} \mathrm{N}$; (b) crop, $117^{\circ} 29^{\prime} 35^{\prime \prime} \mathrm{E}, 33^{\circ} 23^{\prime} 10^{\prime \prime} \mathrm{N}$; (c) needle leaf evergreen tree, $118^{\circ} 52^{\prime} 08^{\prime \prime} \mathrm{E}, 28^{\circ} 30^{\prime} 32^{\prime \prime} \mathrm{N}$; and (d) grass, $114^{\circ} 47^{\prime} 17^{\prime \prime} \mathrm{E}, 38^{\circ} 59^{\prime} 37^{\prime \prime} \mathrm{N}$.

In order to better identify the difference between the two datasets, linear regression was run on these four samples with yearly combined NDVI (Figure 11). All the smoothed NDVI series had a lower value than the raw NDVI. Nevertheless, the slope and the change trajectory of smoothed yearly NDVI series 
were similar with the raw one. The results of Chi-Square Test using a Linear-by-Linear Association model indicated that all the pairs showed significantly consistent tendencies, with the P-values (two-sided) of the four pairs of raw and smoothed yearly series for $0.046,0.006,0.027$, and 0.003 . Therefore, although there were changes in NDVI series, the annual trend of NDVI series did not change much.

Furthermore, compared with the parametric slopes of $0.0040,0.0157,0.0020$, and 0.0064 in the four sample points, the slopes from the Theil-Sen procedure were 0.0046, 0.0158, 0.0014, and 0.0065, respectively. Since it is uncertain whether the high or low value of annual average NDVI is noise which should be removed, this comparison is only to show the similarity of the two regressions.

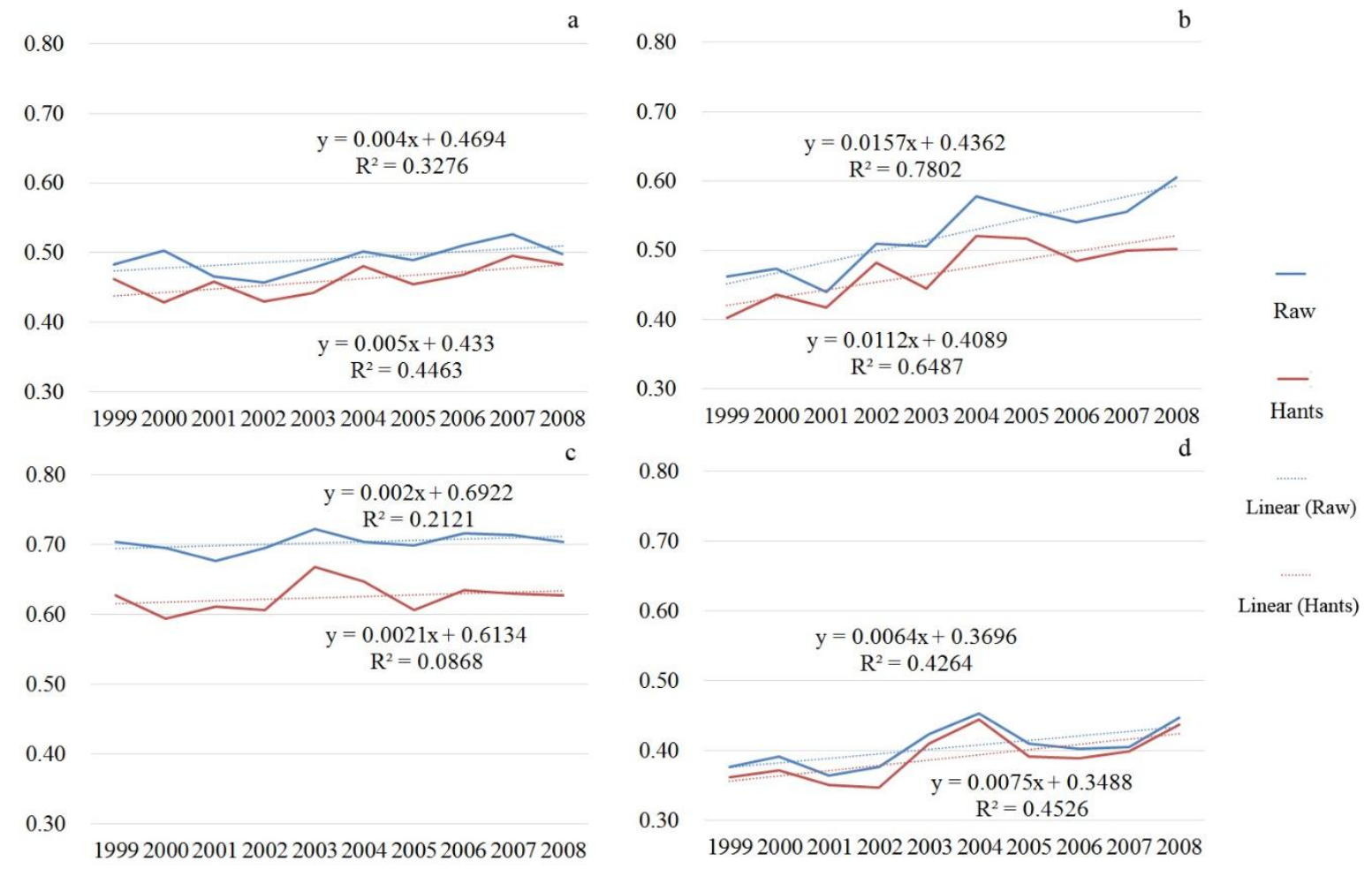

Figure 11. Comparison of the regressed slopes from both raw NDVI and HANTS-filtered NDVI. (a) Broadleaf deciduous tree; (b) crop; (c) needle leaf evergreen tree; and (d) grass.

\subsection{Limitations and Future Research Directions}

In the future, the validation of data sources, innovation of methods, and the study period should be paid more attention. In terms of the data sources, AVHRR GIMMS3g NDVI, and MODIS NDVI/EVI were widely used in quantifying vegetation dynamics [60-63]. As one of the most common data sets, SPOT-VGT NDVI can be used to confirm the trend of vegetation variation using AVHRR GIMMS3g NDVI, MODIS NDVI and EVI. As for methods, simple linear regression is usually used for long time series $[24,64]$. The longer the NDVI time series is, the lower the uncertainties will be. The initial aim of this study is to quantify the environmental evolution in Eastern China every decade. It is common to choose a decade or even less than a decade as the study period in the previous studies [61,65-67]. However, vegetation dynamics quantified using MODIS products including NDVI and EVI for more than a 15 year period is highly recommended in the future studies. 
It should still be noted that the test used to compare unsmoothed versus smoothed NDVI time series is limited, because only four random points cannot fully characterize the total difference between the two data processing results. To compare the maps of the two trends may be a better choice to reveal the difference [50]. However, as we know, what is quantified by the smoothed NDVI is rather an estimation than an actual depiction of vegetation density in the discussion of this study. Since different fitting techniques can result in diverse results, it is in great need to assess the accuracy of the smoothed NDVI data series, and to make sure how to select the most precise fitting algorithm [68]. As the first and important step, except remote sensing images, a ground-based data source truly quantifying vegetation density at a broad scale should be found to make the accuracy analysis. Furthermore, together with the highlighting of non-parametric slope effectiveness, a thorough comparison between OLS and Theil-Sen regression results at the annual scale is also in great need, because the yearly combined NDVI may not be the noise which is often be removed by the non-parametric method.

Meanwhile, the location of meteorological stations may be in relation to the correlations between climate change and vegetation variation. The number of the meteorological stations in Yangtze River Delta is the lowest and, therefore, results have the highest uncertainties. In the future study, integrating the national and basic meteorological stations to update and complete the results should be useful. As for the meteorological stations, further analysis of the impact of climatic factors and anthropogenic activities on vegetation dynamics needs the information of land use and climate condition around the meteorological stations.

The temporal correlation between vegetation dynamics and climate change is determined to clarify the driving effects of climate change on vegetation dynamics. However, the dynamics of the anthropogenic activities in the time series cannot be completely characterized by nighttime light data, and the details of the effects of anthropogenic activities on vegetation changes are still unclear. Thus, the relative importance of the driving effects of climate and anthropogenic factors cannot be accurately determined. In addition, different types of vegetation in the urban areas, rural areas, and urban extending areas may account for the variations of both NDVI value and the change trend. In this study, land use change triggered by urbanization should be the main reason of the difference of mean NDVI, but how to eliminate the interference of different vegetation types is unsolved, which is an interesting topic. In order to identify the driving effects of anthropogenic activities on the vegetation dynamics on the timeline, anthropogenic and climatic factors are needed to be spatially integrated. To achieve this goal, more natural factors, such as topography, soil, and hydrology, and more factors quantifying anthropogenic activities, such as population, economic level, agriculture, and the stage of urban development, are needed to integrate multiple factors at the province or city scale.

\section{Conclusions}

In this study, simple linear regression, partial correlation analysis, and other methodologies were used to discuss vegetation dynamics and associated driving forces, with the application of long time-series data from SPOT-VGT remote sensing images. The main findings were as follows: (i) during the study period, the general density of vegetation increased in Eastern China, and there were large spatial variations in the linear trends of vegetation dynamics. The vegetation improvement was concentrated in Yangtze River Delta and the vegetation degradation was concentrated in the other developed areas, such 
as Beijing-Tianjin-Hebei region and Pearl River Delta; (ii) climatic factors, such as temperature and precipitation, influenced the NDVI change, and the impact showed distinct spatial variation. In Northeast China and Pearl River Delta, annual NDVI change was mainly dominated by temperature; in Bohai Rim, annual NDVI change was mainly affected by precipitation; and in Yangtze River Delta, the driving forces of temperature and precipitation were almost equaled to each other; and (iii) anthropogenic activities, such as urbanization process, induced significant vegetation degradation shown by the increased vegetation density and the smaller slope of vegetation change in the urban areas than those in the rural areas, as well as the larger vegetation density and change slope in the urban extending areas than those in the urban areas, whereas smaller than those in the rural areas. The impact of anthropogenic activities on vegetation density had an accumulative effect during the time series, and the impact of anthropogenic activities on vegetation change trend varied in different urbanization stages.

\section{Acknowledgments}

This research was financially supported by the National Natural Science Foundation of China (No. 41322004).

\section{Author Contributions}

Jian Peng, You Li, and Yanglin Wang conceived and designed the study. Jian Peng, You Li, and Lu Tian wrote the first draft of the article. Jian Peng and Yanxu Liu reviewed and edited the first draft of the article. All authors read and approved the submitted manuscript, agreed to be listed, and accepted the version for publication.

\section{Conflicts of Interest}

The authors declare no conflict of interest.

\section{References}

1. Piao, S.L.; Fang J.Y. Seasonal changes in vegetation activity in response to climate changes in China between 1982 and 1999. Acta Geogr. Sinica 2003, 58, 119-125. (In Chinese)

2. Hutchinson, J.M.S.; Jacquin, A.; Hutchinson, S.L.; Verbesselt, J. Monitoring vegetation change and dynamics on U.S. Army training lands using satellite image time series analysis. J. Environ. Manage. 2015, 150, 355-366.

3. Wu, D.H.; Wu, H.; Zhao, X.; Zhou, T.; Tang, B.J.; Zhao, W.Q.; Jia, K. Evaluation of spatiotemporal variations of global fractional vegetation cover based on GIMMS NDVI data from 1982 to 2011. Remote Sens. 2014, 6, 4217-4239.

4. Jalut, G.; Dedoubat, J.J.; Fontugne, M.; Otto, T. Holocene circum-Mediterranean vegetation changes: climate forcing and human impact. Quatern. Int. 2009, 200, 4-18.

5. Turner, B.L.; Skole, D.; Sanderson, S.; Fischer, G.; Fresco, L.; Leemans, R. Land-Use and Land-Cover Change, Science/Research Plan; International Geosphere-Biosphere Programme: Wageningen, The Netherlands, 1995. 
6. Bao, G.; Qin, Z.H.; Bao, Y.H.; Zhou, Y.; Li, W.J.; Sanjjav, A. NDVI-based long-term vegetation dynamics and its response to climatic change in the Mongolian Plateau. Remote Sens. 2014, 6, 8337-8358.

7. Feurdean, A.; Perşoiu, A.; Tanţău, I.; Stevens, T.; Magyari, E.K.; Onac, B.P.; Marković, S.; Andrič, M.; Connor, S.; Fărcaş, S.; et al. Climate variability and associated vegetation response throughout Central and Eastern Europe (CEE) between 60 and 8 ka. Quat. Sci. Rev. 2014, 106, 206-224.

8. Li, Z.Q.; Guo, X.L. Detecting climate effects on vegetation in Northern Mixed Prairie using NOAA AVHRR 1-km time-series NDVI data. Remote Sens. 2012, 4, 120-134.

9. Xu, G.; Zhang, H.F.; Chen, B.Z.; Zhang, H.R.; Innes, J.L.; Wang, G.Y.; Yan, J.W.; Zheng, Y.H.; Zhu, Z.C.; Myneni, R.B. Changes in vegetation growth dynamics and relations with climate over China's landmass from 1982 to 2011. Remote Sens. 2014, 6, 3263-3283.

10. Zhou, Y.; Zhang, L.; Fensholt, R.; Wang, K.; Vitkovskaya, I.; Tian, F. Climate contributions to vegetation variations in Central Asian drylands: Pre- and Post- USSR Collapse. Remote Sens. 2015, 7, 2449-2470.

11. Myneni, R.B.; Keeling, C.D.; Tucker, C.J.; Asrar, G.; Nemani, R.R. Increased plant growth in the northern high latitudes from 1981 to 1991. Nature 1997, 386, 698-702.

12. Myneni, R.B.; Tucker, C.J.; Asrar, G.; Keeling, C.D. Interannual variations in satellite-sensed vegetation index data from 1981 to 1991. J. Geophys. Res. 1998, 103, 6145-6160.

13. Kawabata, A.; Ichii, K.; Yamaguchi, Y. Global monitoring of interannual changes in vegetation activities using NDVI and its relationships to temperature and precipitation. Int. J. Remote Sens. 2001, 22, 1377-1382.

14. Nemani, R.R.; Keeling, C.D.; Hashimoto, H.; Jolly, W.M.; Piper, S.C.; Tucker, C.J.; Myneni, R.B.; Running, S.W. Climate-driven increases in global terrestrial net primary production from 1982 to 1999. Science 2003, 300, 1560-1563.

15. Azzali, S.; Menenti, M. Mapping vegetation-soil-climate complexes in southern Africa using temporal Fourier analysis of NOAA-AVHRR NDVI data. Int. J. Remote Sens. 2000, 21, 973-996.

16. Senay, G.B.; Elliott, R.L. Combining AVHRR-NDVI and landuse data to describe temporal and spatial dynamics of vegetation. Forest Ecol. Manag. 2000, 128, 83-91.

17. Weiss, E.; Marsh, S.E.; Pfirman, E.S. Application of NOAA-AVHRR NDVI time-series data to assess changes in Saudi Arabia's rangelands. Int. J. Remote Sens. 2001, 22, 1005-1027.

18. Zhou, L.M.; Tucker, C.J.; Kaufmann, R.K.; Slayback, D.; Shabanov, N.V.; Myneni, R.B. Variations in northern vegetation activity inferred from satellite data of vegetation index during 1981 to 1999. J. Geophys. Res. 2001, 106, 20069-20083.

19. Pelkey, N.W.; Stoner, C.J.; Caro, T.M. Assessing habitat protection regimes in Tanzania using AVHRR NDVI composites: Comparisons at different spatial and temporal scales. Int. J. Remote Sens. 2003, 24, 2533-2558.

20. Stow, D.; Daeschner, S.; Hope, A.; Douglas, D.; Petersen, A.; Myneni, R.; Zhou, L.; Oechel, W. Variability of the seasonally integrated normalized difference vegetation index across the north slope of Alaska in the 1990s. Int. J. Remote Sens. 2003, 24, 1111-1117.

21. Yu, F.F.; Price, K.P.; Ellis, J.; Shi, P.J. Response of seasonal vegetation development to climatic variations in Eastern Central Asia. Remote Sens. Environ. 2003, 87, 42-54. 
22. Gonzalez-Alonso, F.; Cuevas, J.M.; Calle, A.; Casanova, J.L.; Romo, A. Spanish vegetation monitoring during the period 1987-2001 using NOAA-AVHRR images. Int. J. Remote Sens. 2004, 25, 3-6.

23. Tarnavsky, E.; Garrigues, S.; Brown, M.E. Multiscale geostatistical analysis of AVHRR, SPOT-VGT, and MODIS global NDVI products. Remote Sens. Environ. 2008, 112, 535-549.

24. Fensholt, R.; Proud, S.R. Evaluation of Earth Observation based global long term vegetation trends-Comparing GIMMS and MODIS global NDVI time series. Remote Sens. Environ. 2012, 119, 131-147.

25. Peng, J.; Liu, Y.H.; Shen, H.; Han, Y.N.; Pan, Y.J. Vegetation coverage change and associated driving forces in mountain areas of Northwestern Yunnan, China using RS and GIS. Environ. Monit. Assess. 2012, 184, 4787-4798.

26. Ichii, K.; Kawabata, A.; Yamaguchi, Y. Global correlation analysis for NDVI and climatic variables and NDVI trends: 1982-1990. Int. J. Remote Sens. 2002, 23, 3873-3878.

27. Shabanov, N.V.; Zhou, L.M.; Knyazikhin, Y.; Myneni, R.B.; Tucker, C.J. Analysis of interannual changes in northern vegetation activity observed in AVHRR data from 1981 to 1994. IEEE Trans. Geosci. Remote Sens. 2002, 40, 115-130.

28. Gong, D.Y.; Ho, C.H. Detection of large-scale climate signals in spring vegetation index (normalized difference vegetation index) over the Northern Hemisphere. J. Geophys. Res. 2003, doi:10.1029/2002JD002300.

29. Gong, D.Y.; Shi, P.J. Northern hemispheric NDVI variations associated with large-scale climate indices in spring. Int. J. Remote Sens. 2003, 24, 2559-2566.

30. Zhou, L.; Kaufmann, R.K.; Tian, Y.; Myneni, R.B.; Tucker, C.J. Relation between interannual variations in satellite measures of northern forest greenness and climate between 1982 and 1999. J. Geophys. Res. 2003, doi:10.1029/2002JD002510.

31. Paruelo, J.M.; Lauenroth, W.K. Interannual variability of NDVI and its relationship to climate for North American shrublands and grasslands. J. Biogeogr. 1998, 25, 721-733.

32. Yang, L.M., Wylie, B.K., Tieszen, L.L., Reed, B.C. An analysis of relationships among climate forcing and time-integrated NDVI of grasslands over the U.S. northern and central Great Plains. Remote Sens. Environ. 1998, 65, 25-37.

33. Ji, L.; Peters, A.J. A spatial regression procedure for evaluating the relationship between AVHRR-NDVI and climate in the northern Great Plains. Int. J. Remote Sens. 2004, 25, 297-311.

34. Peng, J.; Liu, Z.H.; Liu, Y.H.; Wu, J.S.; Han, Y.N. Trend analysis of vegetation dynamics in Qinghai-Tibet Plateau using Hurst Exponent. Ecol. Indic. 2012, 14, 28-39.

35. Lu, D.S.; Xu, X.F.; Tian, H.Q.; Moran, E.; Zhao, M.S.; Running, S. The effects of urbanization on net primary productivity in southeastern China. Environ. Manage. 2010, 46, 404-410.

36. Xu, C.; Liu, M.; An, S.; Chen, J.M.; Yan, P. Assessing the impact of urbanization on regional net primary productivity in Jiangyin County, China. J. Environ. Manage. 2007, 85, 597-606.

37. Peng, J.; Wu, J.S.; Yin, H.; Li, Z.G.; Chang, Q.; Mu, T.L. Rural land use change during 1986-2002 in Lijiang, China, based on remote sensing and GIS data. Sensors 2008, 8, 8201-8223.

38. Liu, Y.X.; Wang, Y.L.; Peng, J.; Du, Y.Y.; Liu, X.F.; Li, S.S.; Zhang, D.H. Correlations between urbanization and vegetation degradation across the world's metropolises using DMSP/OLS nighttime light data. Remote Sens. 2015, 7, 2067-2088. 
39. Chen, J.; Jönsson, P.; Tamura, M.; Gu, Z.; Matsushita, B.; Eklundh, L. A simple method for reconstructing a high-quality NDVI time-series data set based on the Savitzky-Golay filter. Remote Sens. Environ. 2004, 91, 332-344.

40. Cihlar, J.; Ly, H.; Li, Z.Q.; Chen, J.; Pokrant, H.; Huang, F.T. Multitemporal, multichannel AVHRR data sets for land biosphere studies-Artifacts and corrections. Remote Sens. Environ. 1997, 60, $35-57$.

41. Gutman, G.G. Vegetation indices from AVHRR: An update and future prospects. Remote Sens. Environ. 1991, 35, 121-136.

42. Jin, Z.; Xu, B. A novel compound smoother-RMMEH to reconstruct MODIS NDVI time series. IEEE Geosci. Remote Sens. 2013, 10, 942-946.

43. Ren, J.; Chen, Z.; Zhou, Q.; Tang, H. Regional yield estimation for winter wheat with MODIS-NDVI data in Shandong, China. Int. J. Appl. Earth Obs. 2008, 10, 403-413.

44. Brooks, E.B.; Thomas, V.A.; Wynne, R.H.; Coulston, J.W. Fitting the multitemporal curve: A Fourier series approach to the missing data problem in remote sensing analysis. IEEE Trans. Geosci. Remote Sens. 2012, 50, 3340-3353.

45. Beck, P.S.A.; Atzberger, C.; Høgda, K.A.; Johansen, B.; Skidmore, A.K. Improved monitoring of vegetation dynamics at very high latitudes: A new method using MODIS NDVI. Remote Sens. Environ. 2006, 100, 321-334.

46. Jönsson, P.; Eklundh, L. Seasonality extraction by function fitting to time-series of satellite sensor data. IEEE Trans Geosci. Remote Sens. 2002, 40, 1824-1832.

47. Zhou, J.; Li, J.; Menenti, M. Reconstruction of global MODIS NDVI time series: Performance of Harmonic Analysis of Time Series (HANTS). Remote Sens. Environ. 2015, 163, 217-228.

48. National Geophysical Data Center. The Defense Meteorological Satellite Program (DMSP)/Operational Line-Scan System (OLS) nighttime stable light data (NTL) data (1999-2008). Available online: http://www.ngdc.noaa.gov/dmsp/downloadV4composites.html.

49. He, C.Y.; Shi, P.J.; Li, J.G.; Chen, J.; Pan, Y.Z.; Li, J.; Zhuo, L.; Ichinose, T. Restoring urbanization process in China in the 1990s by using non-radiance-calibrated DMSP/OLS nighttime light imagery and statistical data. Chin. Sci. Bull. 2006, 51, 1614-1620.

50. Fensholt, R.; Horion, S.; Tagesson, T.; Ehammer, A; Ivits, E.; Rasmussen, K. Global-scale mapping of changes in ecosystem functioning from earth observation-based trends in total and recurrent vegetation. Global Ecol. Biogeogr. 2015, 24, 1003-1017.

51. Tottrup, C.; Rasmussen, M.S. Mapping long-term changes in savannah crop productivity in Senegal through trend analysis of time series of remote sensing data. Agr. Ecosyst. Environ. 2004, 103, 545-560.

52. Herrmann, S.M.; Anyamba, A.; Tucker, C.J. Recent trends in vegetation dynamics in the African Sahel and their relationship to climate. Global Environ. Chang. 2005, 15, 394-404.

53. Camberlin, P.; Martiny, N.; Philippon, N.; Richard, Y. Determinants of the interannual relationships between remote sensed photosynthetic activity and rainfall in tropical Africa. Remote Sens. Environ. 2007, 106, 199-216.

54. Hansen, P.M.; Schjoerring, J.K. Reflectance measurement of canopy biomass and nitrogen status in wheat crops using normalized difference vegetation indices and partial least squares regression. Remote Sens. Environ. 2003, 86, 542-553. 
55. Li, J.X.; Li, C.; Zhu, F.G.; Song, C.H.; Wu, J.G. Spatiotemporal pattern of urbanization in Shanghai, China between 1989 and 2005. Landsc. Ecol. 2013, 28, 1545-1565.

56. Su, S.L.; Ma, X.Y.; Xiao, R. Agricultural landscape pattern changes in response to urbanization at ecoregional scale. Ecol. Indic. 2014, 40, 10-18.

57. He, C.Y.; Liu, Z.F.; Tian, J.; Ma, Q. Urban expansion dynamics and natural habitat loss in China: A multiscale landscape perspective. Global Change Biol. 2014, 20, 2886-2902.

58. Su, S.L.; Wang, Y.P.; Luo, F.H.; Mai, G.C.; Pu, J. Peri-urban vegetated landscape pattern changes in relation to socioeconomic development. Ecol. Indic. 2014, 46, 477-486.

59. Zhou, J.H.; Yu, B.L.; Qin, J. Multi-level spatial analysis for change detection of urban vegetation at individual tree scale. Remote Sens. 2014, 6, 9086-9103.

60. Evrendilek, F.; Gulbeyaz, O. Deriving vegetation dynamics of natural terrestrial ecosystems from MODIS NDVI/EVI data over Turkey. Sensors 2008, 8, 5270-5302.

61. Caccamo, G.; Chisholm, L.A.; Bradstock, R.A.; Puotinen, M.L. Assessing the sensitivity of MODIS to monitor drought in high biomass ecosystems. Remote Sens. Environ. 2011, 115, 2626-2639.

62. Hwang, T.; Song, C.H.; Bolstad, P.V.; Band, L.E. Downscaling real-time vegetation dynamics by fusing multi-temporal MODIS and Landsat NDVI in topographically complex terrain. Remote Sens. Environ. 2011, 115, 2499-2512.

63. Huete, A.; Didan, K.; Miura, T.; Rodriguez, E.P.; Gao, X.; Ferreira, L.G. Overview of the radiometric and biophysical performance of the MODIS vegetation indices. Remote Sens. Environ. 2002, 83, 195-213.

64. An, Y.Z.; Gao, W.; Gao, Z.Q.; Liu, C.S.; Shi, R.H. Trend analysis for evaluating the consistency of Terra MODIS and SPOT VGT NDVI time series products in China. Front. Earth Sci. 2015, 9 , 125-136.

65. Jarlan, L.; Mangiarotti, S.; Mougin, E.; Mazzega, P.; Hiernaux, P.; Le Dantec, V. Assimilation of SPOT/VEGETATION NDVI data into a sahelian vegetation dynamics model. Remote Sens. Environ. 2008, 112, 1381-1394.

66. Sun, Z.D.; Chang, N.B.; Opp, C. Using SPOT-VGT NDVI as a successive ecological indicator for understanding the environmental implications in the Tarim River Basin, China. J. Appl. Remote Sens. 2010, doi:10.1117/1.3518454.

67. Höpfner, C.; Scherer, D. Analysis of vegetation and land cover dynamics in north-western Morocco during the last decade using MODIS NDVI time series data. Biogeosciences 2011, 8, 3359-3373.

68. Geng, L.; Ma, M.; Wang, X.; Yu, W.; Jia, S.; Wang, H. Comparison of eight techniques for reconstructing multi-satellite sensor time-series NDVI data sets in the Heihe River Basin, China. Remote Sens. 2014, 6, 2014-2049.

(C) 2015 by the authors; licensee MDPI, Basel, Switzerland. This article is an open access article distributed under the terms and conditions of the Creative Commons Attribution license (http://creativecommons.org/licenses/by/4.0/). 